\title{
Nucleus Accumbens $\mu$-Opioids Regulate Intake of a High-Fat Diet via Activation of a Distributed Brain Network
}

\author{
M. J. Will, E. B. Franzblau, and A. E. Kelley \\ Department of Psychiatry, University of Wisconsin-Madison, Madison, Wisconsin 53719
}

Endogenous opioid peptides within the nucleus accumbens, a forebrain site critical for the regulation of reward-related behavior, are believed to play an important role in the control of appetite. In particular, this system is thought to mediate the hedonic aspects of food intake, governing the positive emotional response to highly palatable food such as fat and sugar. Previous work has shown that intraaccumbens administration of the $\mu$-opioid agonist D-Ala2,Nme-Phe4,Glyol5-enkephalin (DAMG0) markedly increases food intake and preferentially enhances the intake of palatable foods such as fat, sucrose, and salt. Using information from recently performed c-fos mapping experiments, we sought to explore the involvement of structures efferent to the nucleus accumbens in this feeding response. Free-feeding rats with dual sets of bilateral cannulas aimed at the nucleus accumbens and one of several output structures were infused with DAMGO $(0,0.25 \mu \mathrm{g} / 0.5 \mu \mathrm{l})$ in the accumbens, and fat intake was measured over a $2 \mathrm{hr}$ period. Concurrent temporary inactivation with the $\mathrm{GABA}_{\mathrm{A}}$ agonist muscimol (5-20 ng/0.25 $\mu \mathrm{l}$ ) of the dorsomedial hypothalamic nucleus, lateral hypothalamus, ventral tegmental area, or the intermediate region of the nucleus of the solitary tract blocked the robust increase in fat intake induced by intra-accumbens DAMGO at doses of muscimol that did not affect general motor activity. Muscimol alone also inhibited and augmented baseline fat intake in the lateral and dorsomedial hypothalamic nuclei, respectively. These results suggest that intake of energy-dense palatable food is controlled by activity in a neural network linking ventral striatal opioids with diencephalic and brainstem structures.

Key words: feeding; opioids; nucleus accumbens; muscimol; DAMGO; palatability; high-fat diet; hypothalamus; nucleus of the solitary tract; ventral tegmental area; hippocampus

\section{Introduction}

The neural substrates mediating the subjective pleasure that humans derive from certain energy-dense foods, such as those high in sugar and fat, enable adaptive feeding behavior during times when food is scarce. However, in modern Western societies in which food is abundant, activation of these systems can provide a "false benefit" signal, resulting in overeating and obesity. Of the neural systems that have been shown to play a role in feeding behavior, endogenous opioid peptides have received particular attention (Martin et al., 1963; Cooper and Kirkham, 1993). Indeed, studies have focused on multiple aspects of feeding regulation, ranging from the influence of opioids on energy homeostasis and macronutrient selection to taste reactivity and food motivation (Levine and Billington, 1989; Carr, 1996; Glass et al., 1999; Kelley et al., 2002). Although the precise nature of opioidinduced feeding remains elusive, evidence from both animal (Cooper, 1983; Carr and Simon, 1984; Giraudo et al., 1993; Johnson et al., 1993; Weldon et al., 1996) and human (Drewnowski et al., 1992; Yeomans and Gray, 1996; Yeomans and Gray, 1997) studies suggests that opioids enhance food palatability and food reward.

Although administration of opioids into multiple brain regions influences feeding behavior (Stanley et al., 1988), the nucleus accumbens has been shown to be particularly involved in

\footnotetext{
Received Aug. 23, 2002; revised Jan. 7, 2003; accepted Jan. 9, 2003.

This research was supported by National Institute on Drug Abuse Grant DA09311 and National Institutes of Health Fellowship F32 DA14751.

Correspondence should be addressed to Dr. Matthew J. Will, Department of Psychiatry, University of WisconsinMadison, 6001 Research Park Boulevard, Madison, WI 53719. E-mail: mjwill@wisc.edu.

Copyright $\odot 2003$ Society for Neuroscience $\quad 0270-6474 / 03 / 232882-07 \$ 15.00 / 0$
}

mediating the affective response to food (Mucha and Iversen, 1986; Bakshi and Kelley, 1993b; Zhang et al., 1998). Furthermore, the anatomical organization of the afferent and efferent connections to the nucleus accumbens suggests that it is ideally positioned to translate the affective assessment of food into the behavioral expression of feeding. Indeed, significant projections to the opioid-sensitive feeding zone within the ventral striatum arrive via the gustatory cortex (Braun et al., 1982), nucleus of the solitary tract (Brog et al., 1993), and rostral basal amygdala (Wright and Groenewegen, 1996). In addition to processing critical orosensory information, the nucleus accumbens projects to the lateral and dorsomedial hypothalamic nucleus, substantia nigra, ventral pallidum, and ventral tegmental area (Haber et al., 1990; Heimer et al., 1991), structures that potentially contribute to the motor expression of feeding. Although numerous studies have demonstrated the involvement of these efferent and afferent regions of the accumbens in feeding behavior (Glass et al., 1999), the role of the accumbens as a critical site for integrating the activity of these areas is essentially unexplored. More importantly, the specific role of intra-accumbens opioids in mediating the coordination of the feeding response is unknown.

We have shown previously that intra-accumbens administration of the $\mu$-agonist D-Ala2, NMe-Phe4, Glyol5-enkephalin (DAMGO) strongly increases the intake of highly palatable food (Bakshi and Kelley, 1993a; Zhang and Kelley, 1997; Zhang et al., 1998). In addition, intra-accumbens DAMGO selectively activates circuitry involving hypothalamic, limbic, and brainstem areas, as measured by c-fos expression (Zhang and Kelley, 2000). Using that study as a guide, the current study was designed to determine whether activation of these regions was critical for 
mediating the enhanced feeding response observed after administration of intra-accumbens DAMGO. We used a "temporary lesion" approach by reversibly blocking selected sites with bilateral administration of the $\mathrm{GABA}_{\mathrm{A}}$ agonist muscimol before intra-accumbens DAMGO and assessed intake levels of a high-fat diet.

\section{Materials and Methods}

Subjects. Fifty-two adult male Sprague Dawley rats (Harlan Sprague Dawley, Indianapolis, IN) weighing 300-400 gm were housed in groups of two in Plexiglas cages in a climate-controlled colony room of $22^{\circ} \mathrm{C}$. The subjects were maintained on a $12 \mathrm{hr}$ light/dark cycle, and all experiments were conducted during the light phase $(7$ A.M.-7 P.M.). Subjects had ad libitum access to laboratory chow and drinking water before and throughout the experiment. All subjects were naive and allowed a minimum of 1 week adaptation followed by $2 \mathrm{~d}$ of handling before the beginning of all experiments. Experimental and control groups contained seven to nine subjects unless noted otherwise. All experimental procedures were in accord with protocols approved by the University of Wisconsin Institutional Animal Care and Use Committee.

Surgery. For surgery, animals were anesthetized with a mixture of ketamine and xylazine $(90 \mathrm{mg} / \mathrm{kg}$ and $9 \mathrm{mg} / \mathrm{kg}$, respectively; Sigma, St. Louis, MO), and bilateral guide stainless steel cannulas (23 gauge, 10 $\mathrm{mm}$ ) were stereotaxically implanted into two brain regions, the nucleus accumbens and other selected sites. Therefore, each subject was implanted with four cannulas. Guide cannulas were secured to the skull with stainless steel screws and light curable resin (Dental Supply of New England, Boston, MA) using standard flat skull techniques. After surgery, wire stylets were placed in the guide cannulas to prevent occlusion. Coordinates for the aimed sites were as follows (in $\mathrm{mm}$ from bregma): nucleus accumbens (ACC): anteroposterior (AP) 1.4, mediolateral (ML) \pm 1.8 , dorsoventral (DV) -7.8 ; lateral hypothalamus (LH): AP -2.8 , ML $\pm 1.8, \mathrm{DV}-8.7$; dorsomedial hypothalamic nucleus (DMH): AP -2.8 ; $\mathrm{ML} \pm 0.7$; $\mathrm{DV}-8.7$; ventral tegmental area (VTA): AP $-5.6, \mathrm{ML} \pm 0.5$; DV -8.3 ; intermediate region of the nucleus of the solitary tract (iNTS): $\mathrm{AP}-13.3, \mathrm{ML} \pm 0.7, \mathrm{DV}-8.5$; dorsal hippocampus (dHC): AP -2.8; $\mathrm{ML} \pm 1.9, \mathrm{DV}-3.6$. Rats were allowed at least $7 \mathrm{~d}$ recovery before the start of behavioral testing.

Drugs and microinjection. DAMGO (Research Biochemicals, Natick, MA) and muscimol (Sigma) were both dissolved in sterile $0.9 \%$ saline. The vehicle control was always sterile $0.9 \%$ saline. Infusions were delivered with a microdrive pump (Harvard Apparatus, South Natick, MA), connected via polyethylene tubing (PE-10), while animals were gently hand-held. Thirty-three gauge $12.5 \mathrm{~mm}$ injectors were used, thus extending $2.5 \mathrm{~mm}$ beyond the end of the guide cannulas. The rate of injection was $0.32 \mu \mathrm{l} / \mathrm{min}$ for the accumbens and $0.16 \mu \mathrm{l} / \mathrm{min}$ for all other structures, with the total duration of infusion being $93 \mathrm{sec}$, resulting in 0.5 and $0.25 \mu \mathrm{l}$ volumes, respectively. One additional minute was allowed for diffusion. Injectors then were removed, and the stylets were replaced before the subjects were placed in their test cages.

Behavioral assessment of feeding. This series of experiments was designed to determine the consequence of inactivating five different structures on the feeding response produced by intra-accumbens DAMGO. Six groups were used with bilateral cannulas implanted in the nucleus accumbens and one of five output structures: LH, DMH, VTA, NTS, and dHC. The dHC served as a control site, because unlike the other four sites, it does not receive direct projections from the accumbens and was not activated by intra-accumbens DAMGO administration (our unpublished observations). All behavioral testing began 1 week after surgery in a room distinct from the animal colony, in individual hanging wire cages measuring $25 \times 20 \times 20 \mathrm{~cm}$. A water bottle and preweighed jars containing high-fat diet (Teklad Diets, Madison, WI) were attached to the cages. The high-fat diet contained $327.6 \mathrm{gm} / \mathrm{kg}$ vitamin-free casein, $4.9 \mathrm{gm} / \mathrm{kg}$ DL-methionine, $441.2 \mathrm{gm} / \mathrm{kg}$ shortening, $77.7 \mathrm{gm} / \mathrm{kg}$ safflower oil, 76.3 $\mathrm{gm} / \mathrm{kg}$ cellulose, $53.3 \mathrm{gm} / \mathrm{kg}$ mineral mix, $15.2 \mathrm{gm} / \mathrm{kg}$ vitamin mix, and $3.8 \mathrm{gm} / \mathrm{kg}$ choline chloride. Subjects were placed in these cages for $2 \mathrm{hr}$ daily until stable food consumption across $3 \mathrm{~d}$ was obtained, which was usually in $6 \mathrm{~d}$. At the end of each testing day, the diet jars were removed and weighed, and the corresponding food intake in grams was calculated. To acclimate the rats to the test procedure, subjects were given $2 \mathrm{~d}$ of sham injections over the last $2 \mathrm{~d}$ of the baseline period. On the first day of this acclimation procedure, a $10 \mathrm{~mm}$ injector was inserted and left in place for $2 \mathrm{~min}$, with no volume injected. The following day, a $12.5 \mathrm{~mm}$ injector was inserted, and saline was administered for $93 \mathrm{sec}$. Using a within-subjects design, all groups of rats received each of four drug treatment combinations on four separate treatment days in a counterbalanced order. On each test day, muscimol (5 or $20 \mathrm{ng} / 0.25 \mu \mathrm{l}$ per side bilaterally depending on the experiment, see below) or saline was infused into the selected site followed immediately by DAMGO $(0.5 \mu \mathrm{g} / 0.5 \mu \mathrm{l}$ per side bilaterally) or saline into the accumbens, thus resulting in four possible treatment combinations. The $2 \mathrm{hr}$ testing session began immediately after the last injection. There was at least $1 \mathrm{~d}$ spaced between treatment days. The DAMGO dose, which results in a robust increase in fat intake, was selected on the basis of previous studies (Bakshi and Kelley, 1993a; Zhang et al., 1998; Zhang and Kelley, 2000). The muscimol dose of $20 \mathrm{ng}$ was chosen on the basis of pilot experiments, which indicated that this dose produced minimized effects on baseline feeding and activity. However, in some pilot studies, it was determined that $20 \mathrm{ng}$ did result in reduced activity compared with controls, and therefore a lower muscimol dose of $5 \mathrm{ng}$ was used in the LH and NTS experiments.

Behavioral assessment of locomotor activity. This experiment was designed to assess the influence of muscimol on the general activity of subjects, because a suppression of baseline and DAMGO-induced feeding could possibly be interpreted as a nonspecific reduction of motor behavior. Additional groups of rats were implanted with only one set of bilateral cannulas aimed either at the LH, DMH, VTA, and NTS (same coordinates as above; $n=4$ for LH, DMH, VTA; $n=3$ for NTS). Before the experiment, subjects were given $2 \mathrm{~d}$ of exposure to the activity cage (located in a separate room) and were assessed for baseline activity. Activity cages were clear polycarbonate locomotor activity testing cages (San Diego Instruments, San Diego, CA). Four photo beams spaced at regular intervals along the bottom length of the cages recorded horizontal activity (any beam being broken). Data were collected on an attached $\mathrm{PC}$ across $10 \mathrm{~min}$ intervals for the duration of the session. The activity cages contained wire mesh floors suspended 0.5 inches above the base of the cage, which was covered with aspen chips. Before each session, sham and saline injections were performed to habituate the rats to the injection procedure as was performed in the feeding experiments above. A withingroup design was used with each subject having received all four doses of muscimol $(0,1,5$, or $20 \mathrm{ng})$ in a volume of $0.25 \mu \mathrm{l}$ on 4 separate days. There was at least $1 \mathrm{~d}$ spaced between injections. Activity was assessed for $2 \mathrm{hr}$ immediately after infusion, and then the rats were returned to their home cages.

Histology. After behavioral testing, subjects were overdosed with sodium pentobarbital and perfused transcardially with heparinized saline (200 ml), followed immediately by $500 \mathrm{ml}$ of a $10 \%$ buffered formalin solution. The brains were then removed and placed in $10 \%$ formalin$20 \%$ sucrose for 1 week. Frozen serial sections $(50 \mu \mathrm{m})$ were collected through the entire extent of the injection site, mounted on gelatinized slides, and counterstained with cresyl violet. Cannula placement profiles were then analyzed for accuracy with light microscopy. Data from rats with misplaced cannulas were not included in the analyses. The placements of all cannulas are represented in histological reconstructions and photographs of representative placements for all sites and are located in Figure 1.

Statistical analysis. In the feeding experiments, the weight of fat consumed across treatment groups was analyzed using a one-way repeated measures ANOVA, followed by post hoc orthogonal contrasts of means when appropriate. In the locomotor experiments, total activity levels across the $2 \mathrm{hr}$ period were analyzed using a oneway repeated measures ANOVA, followed by post hoc individual comparisons when appropriate. 


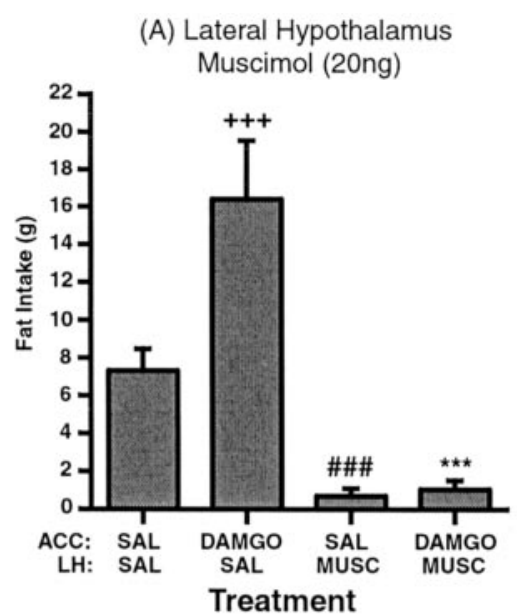

(D) Ventral Tegmental Area Muscimol (20ng)

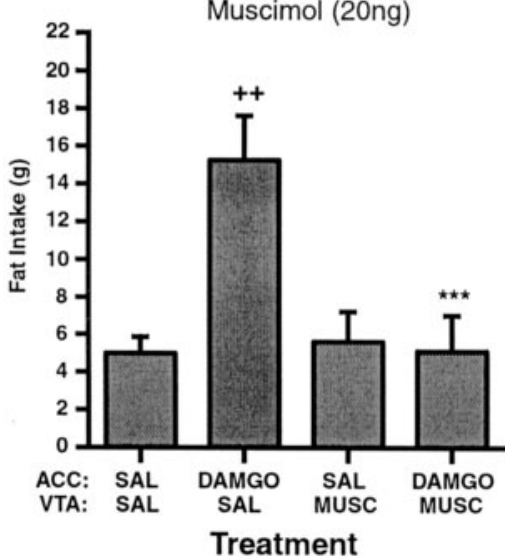

(B) Lateral Hypothalamus Muscimol (5ng)

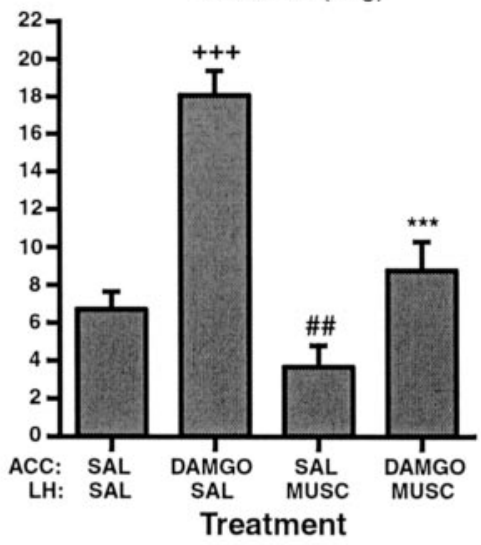

(E) Nucleus of Solitary Tract Muscimol (5ng)

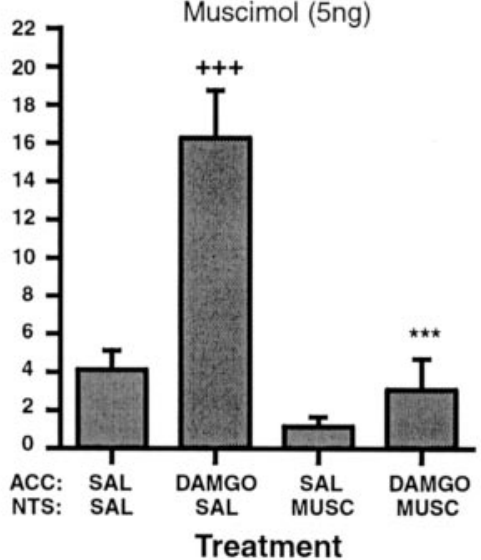

(C) Dorsomedial Hypothalamus Muscimol (20ng)

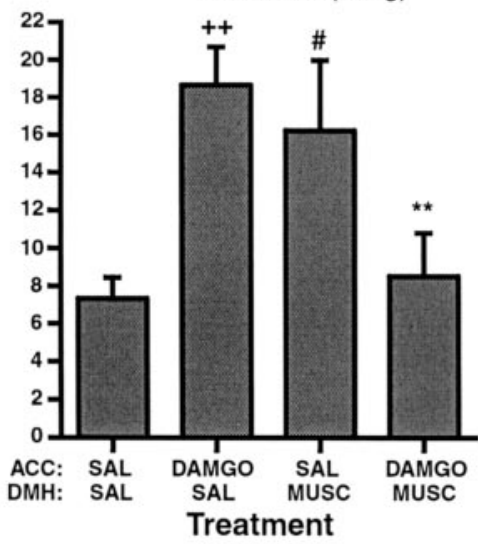

(F) Dorsal Hippocampus (dHC) Muscimol (20ng)

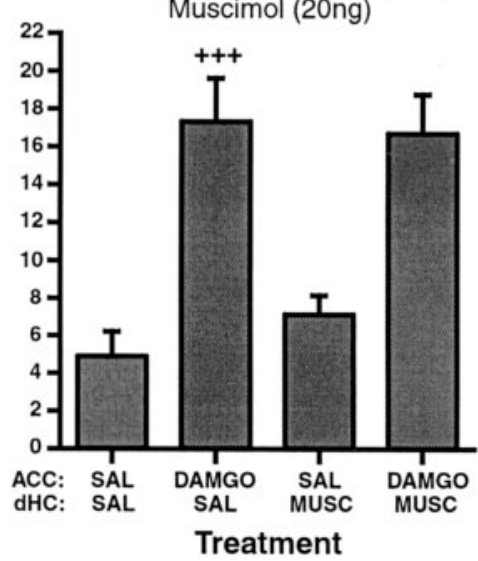

Figure 1. Feeding response to accumbens $\mu$-opioid stimulation (250 ng DAMG0) after muscimol inactivation of selected structures. Values represent group means ( \pm SEM). *, DAMG0/SAL versus DAMGO/MUSC; + , DAMGO/SAL versus SAL/SAL; \#, MUSC/SAL versus SAL/SAL. Level of significance is shown by number of symbols $\left({ }^{*} p<0.05 ;{ }^{* *} p<0.01 ;{ }^{* * *} p<0.001\right)$.

\section{Results}

Feeding response to accumbens $\mu$-opioid stimulation (250 ng DAMGO) after inactivation (muscimol) of selected output structures

Bilateral infusion of intra-accumbens DAMGO significantly enhanced fat intake to $\sim 300 \%$ above saline-injected control levels in all placement groups (Figs. 1, 2, 3). This effect was very robust and very consistent, with the majority of the feeding occurring in the first hour of the $2 \mathrm{hr}$ session. Administration of muscimol into the lateral hypothalamus before intra-accumbens administration of DAMGO prevented this increase. Overall ANOVA of the feeding levels displayed by the $\mathrm{LH}$ group showed a significant effect of treatment $\left(F_{(3,28)}=30.53 ; p<0.0001\right)$ (Fig. $\left.1 A\right)$. Subsequent analysis revealed that the fat intake after administration of $20 \mathrm{ng}$ of muscimol into the $\mathrm{LH}$ immediately before intraaccumbens DAMGO was significantly lower than the intake produced by intra-accumbens DAMGO alone $(p<0.001)$. Administration of intra-LH muscimol by itself significantly reduced feeding compared with saline-injected controls $(p<0.001)$. A subsequent test using a lower dose of intra-LH muscimol (5 ng) also produced a significant effect of treatment $\left(F_{(3,24)}=28.5 ; p<\right.$ 0.0001 ) (Fig. $1 B$ ). Similar to the previous results, post hoc analysis revealed that $5 \mathrm{ng}$ of muscimol significantly blocked the DAMGO-induced increase in feeding $(p<0.001)$ and also significantly reduced feeding by itself $(p<0.01)$, although by a smaller margin than the high dose.
In the DMH subjects, ANOVA also demonstrated a significant effect of treatment $\left(F_{(3,28)}=9.367 ; p<0.0002\right)$ (Fig. 1C). Subsequent analysis revealed that administration of $20 \mathrm{ng}$ muscimol into the DMH prevented the normal increase in feeding produced by intra-accumbens DAMGO ( $p<0.001)$. Surprisingly, feeding was significantly enhanced when intra-DMH muscimol was administered by itself, compared with feeding after saline control treatment $(p<0.001)$.

In the VTA cannulated subjects, ANOVA also revealed a significant effect of treatment $\left(F_{(5,15)}=23.663 ; p<0.0001\right)$ (Fig. $1 D)$. Post hoc analysis revealed that after administration of intraVTA muscimol (20 ng) immediately before intra-accumbens DAMGO, the normal increase in feeding produced by intraaccumbens DAMGO was blocked completely $(p<0.0001)$. When muscimol was administered into the VTA followed by saline into the accumbens, subjects showed no change in feeding levels compared with the saline controls $(p=0.68)$.

ANOVA of the feeding levels in the NTS cannulated group also revealed a significant effect of treatment $\left(F_{(4,12)}=16.885\right.$; $p<0.0001$ ) (Fig. 1E). Administration of intra-NTS muscimol (5 ng) immediately before intra-accumbens DAMGO completely blocked the normal increase in feeding produced by intraaccumbens DAMGO. Muscimol infused into the NTS followed by saline into the accumbens had no effect on feeding compared with controls $(p=0.23)$.

Last, in subjects containing cannulas aimed at the $\mathrm{dHC}$, 

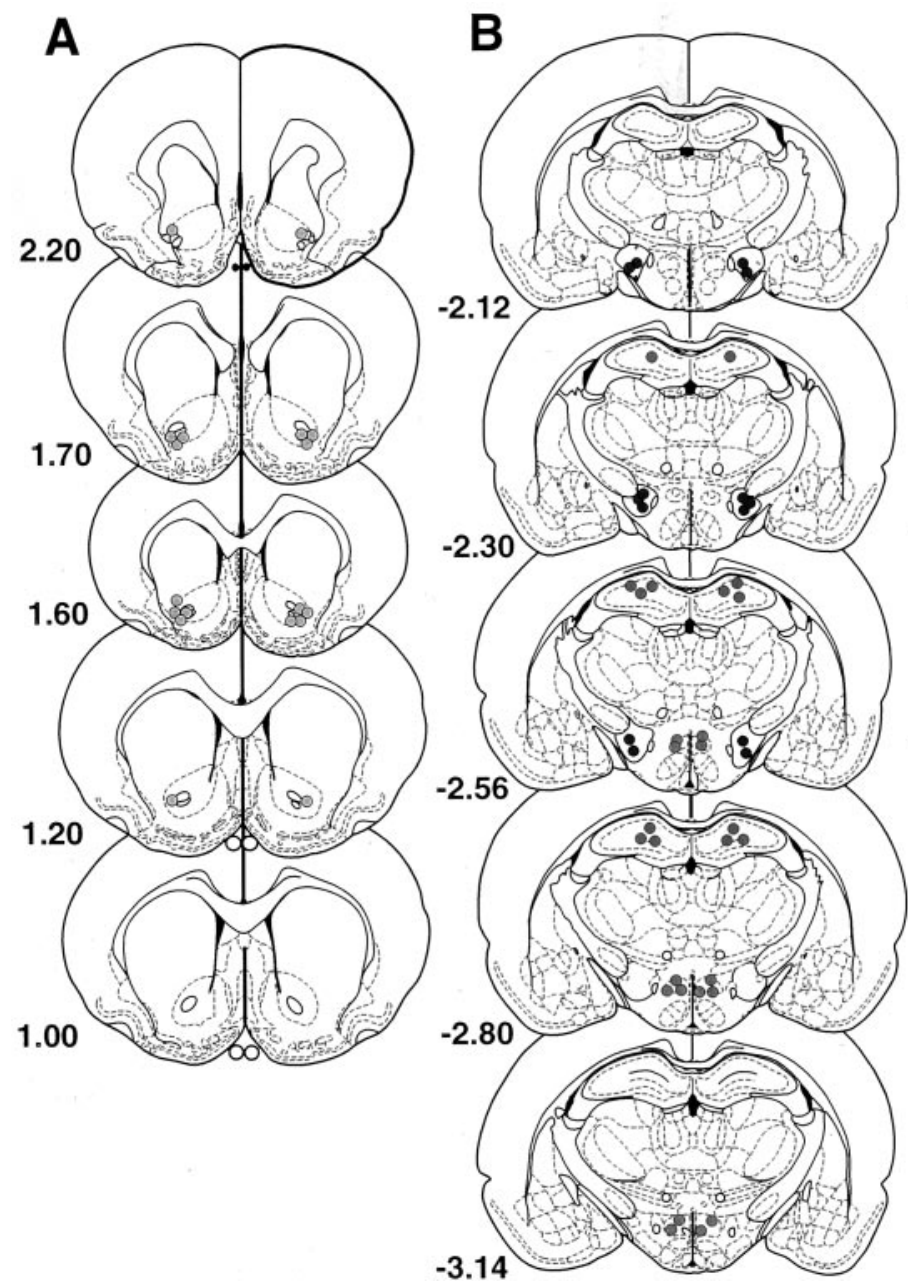
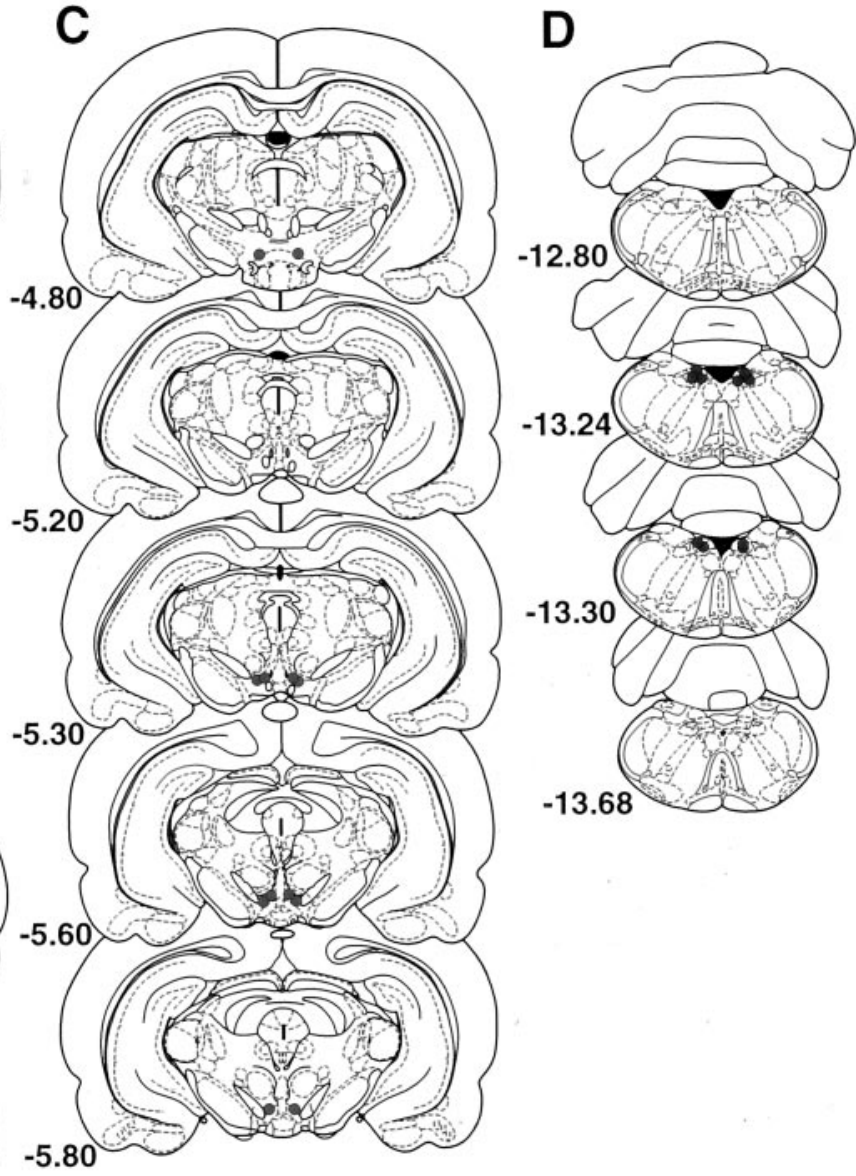

$-13.68$

Figure 2. Histological analysis of microinfusion sites for both the muscimol and DAMGO injections. $A$, Nucleus accumbens placements of one representative study. The remaining slides display the placements of all subjects for each respective study. $B$, Dorsomedial hypothalamus, lateral hypothalamus, dorsal hippocampus $(C)$, ventral tegmental area, $(D)$ nucleus of the solitary tract. Drawings are based on the atlas of Paxinos and Watson (1998).

ANOVA revealed a significant effect of treatment $\left(F_{(6,18)}=40.14\right.$; $p<0.0001$ ) (Fig. $1 F$ ). However, bilateral administration of $20 \mathrm{ng}$ muscimol into the $\mathrm{dHC}$ immediately before intra-accumbens DAMGO had no effect on the normal increase in feeding produced by intra-accumbens DAMGO $(p=0.65)$. When muscimol was infused into the $\mathrm{dHC}$ followed by saline into the accumbens, there was also no effect on feeding compared with controls $(p=0.13)$.

\section{Locomotor response after muscimol administration into structures involved in DAMGO-induced feeding}

In a separate study, we investigated a dose-response effect of muscimol on general activity levels across a $2 \mathrm{hr}$ period after administration into the LH, DMH, VTA, or NTS (Table 1). After saline administration, there was a variable level of activity across placement groups, suggesting an effect produced by either infusion itself or possibly by damage of the respective location of guide cannulas. However, statistical comparison of the activity levels produced by treatment with muscimol produced no significant effects at the doses shown previously to inhibit DAMGOinduced feeding. Individual ANOVAs for each group revealed no effect of drug treatment for subjects with cannulas aimed at the $\mathrm{LH}\left(F_{(3,9)}=1.718 ; p>0.05\right), \mathrm{DMH}\left(F_{(3,9)}=1.374 ; p>0.05\right)$, $\operatorname{VTA}\left(F_{(3,9)}=0.778 ; p>0.05\right)$, or NTS $\left(F_{(2,6)}=2.362 ; p>0.05\right)$.
In addition, post hoc contrast of means analysis determined no significant differences between doses in any of the groups, although certain trends were observed. In the LH, both the $5 \mathrm{ng}$ $(p=0.38)$ and $20 \mathrm{ng}(p=0.23)$ dose did not produce a significant reduction in activity compared with controls. Finally, in the NTS, the $5 \mathrm{ng}(p=0.69)$ and the $20 \mathrm{ng}(p=0.09)$ dose of muscimol had no significant effect on activity compared with the activity of subjects after saline administration.

\section{Discussion}

The present findings demonstrate that the robust feeding normally observed after intra-accumbens DAMGO administration is reversibly blocked by temporary inactivation of any of four distinct regions, including the lateral hypothalamus, dorsomedial hypothalamic nucleus, ventral tegmental area, and the intermediate region of the nucleus of the solitary tract. Indeed, administration of muscimol into any of these four sites before the administration of intra-accumbens DAMGO prevented the increase in fat intake that was normally observed. Administration of muscimol into the dorsal hippocampus, which does not receive direct input from the accumbens and is not activated by intraaccumbens DAMGO, had no effect on the DAMGO-induced feeding response. The only significant effects of muscimol alone on baseline feeding were observed after inactivation of the lateral 

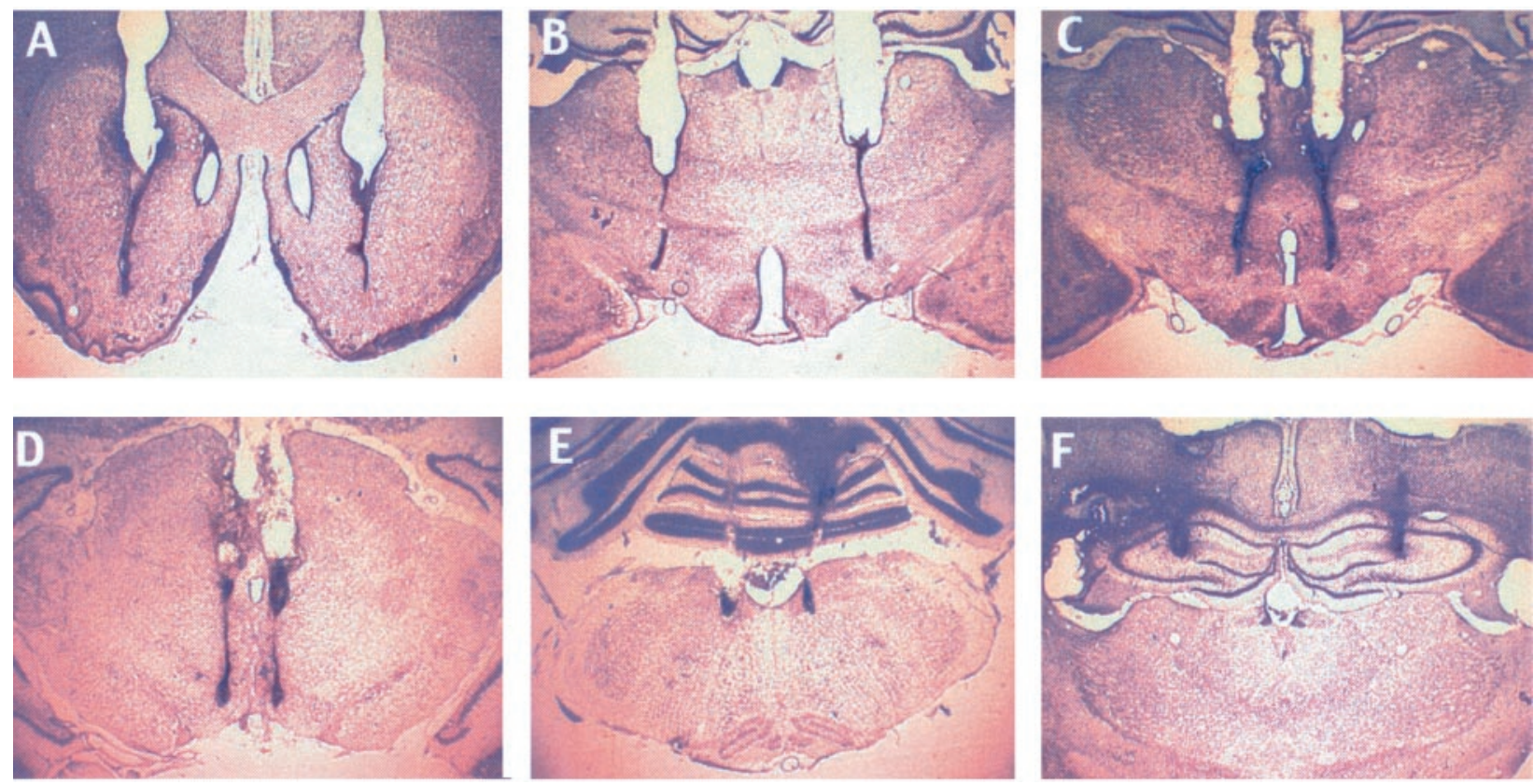

Figure 3. Photomicrographs showing representative cannula placement. $A$, Nucleus accumbens. B, Lateral hypothalamus. C, Dorsomedial hypothalamus. D, Ventral tegmental area. E, Nucleus of the solitary tract. F, Dorsal hippocampus.

Table 1. Horizontal activity after acute administration of muscimol

\begin{tabular}{lllll}
\hline & \multicolumn{4}{l}{ Muscimol dose: $\mathrm{ng} / 0.25 \mu$ l per side bilaterally } \\
\cline { 2 - 5 } & 0 & 1 & 5 & 20 \\
\hline Lateral hypothalamus & $331 \pm 145$ & $443 \pm 102$ & $196 \pm 58^{a}$ & $141 \pm 49^{a}$ \\
Dorsomedial hypothalamus & $266 \pm 81$ & $264 \pm 70$ & $157 \pm 19$ & $142 \pm 30^{a}$ \\
Ventral tegmental area & $512 \pm 44$ & $649 \pm 115$ & $797 \pm 236$ & $772 \pm 209^{a}$ \\
Nucleus of the solitary tract & $128 \pm 54$ & $127 \pm 21$ & $146 \pm 9^{a}$ & $38 \pm 13$
\end{tabular}

Mean ( \pm SEM) values of horizontal activity after bilateral administration of various doses of muscimol into regions that prevented intra-accumbens DAMGO-induced feeding.

${ }^{a}$ Dose of muscimol that significantly blocked feeding in previous experiment.

and dorsomedial hypothalamic regions, where a decrease and increase were found, respectively. Finally, the present findings were shown to be independent of the influence of muscimol on general activity levels. Confirming the previous report that demonstrated selective Fos activation of these hypothalamic, midbrain, and brainstem areas by intra-accumbens DAMGO (Zhang and Kelley, 2000), the present results offer direct support for their involvement as part of a distributed network mediating the expression of intra-accumbens opioid-mediated feeding.

The structures within this distributed network are known to coordinate metabolic, motivational, motor, and autonomic systems, all which have been shown to regulate ingestive behavior. The LH is considered critical for neuroendocrine and autonomic regulation of energy homeostasis and has been studied extensively for its role in feeding behavior (Bernardis and Bellinger, 1993). It contains a complex intrinsic connectivity as well as efferent and afferent pathways to forebrain and hindbrain regions, functioning as a highly interactive area controlling feeding, arousal, and general appetitive behaviors (Bernardis and Bellinger, 1993; Williams et al., 2000). Although it has been shown previously that feeding behavior is disrupted by LH lesion or inactivation, its involvement in intra-accumbens opioid-induced feeding is relatively unexplored. The present study demonstrated that inactivating the LH before intra-accumbens DAMGO infusion completely blocked the increased feeding that was normally observed. In addition, in agreement with previous studies (Ber- nardis and Bellinger, 1993), we found that inactivation of the LH by itself reduced baseline feeding. Considering the highly palatable nature of the diet used in the present studies, this reduction of feeding by LH inactivation alone might be the result of blocking an endogenous opioid signal. Indeed, foods rich in sugar and fat have been shown to release $\beta$-endorphin (Welch et al., 1996), and naltrexone has reduced cravings for similar foods in humans (Yeomans and Gray, 1997). The neurochemical significance of inhibiting the LH may be related to the feeding-related neuropeptides melanin-concentrating hormone and the orexins, which populate this region (Elias et al., 1998). Indeed, these two distinct neuronal populations have a diverse projection pattern, including limbic, cortical, hindbrain, and other hypothalamic regions (Bittencourt et al., 1992; Peyron et al., 1998), and central administration of both peptides has been shown to increase feeding behavior (Qu et al., 1996; Sakurai et al., 1998; Dube et al., 1999; Sweet et al., 1999).

Inactivation of the $\mathrm{DMH}$ also prevented the enhanced feeding observed after intra-accumbens DAMGO administration. Previous studies using permanent lesions of the DMH produce subjects with consistent inhibition of feeding over time (for review, see Bernardis and Bellinger, 1998), with weight slightly under normal (Bellinger and Bernardis, 1999). However, studies conducting reversible temporary inactivation with colchicine administration have produced mixed results (Avrith and Mogenson, 1978; Choi and Dallman, 1999). In the present study, food intake was significantly increased when subjects were administered intra-DMH muscimol followed by saline into the accumbens, a finding similar to that observed after inactivation of the ventromedial hypothalamus (Albert et al., 1971; Kelly et al., 1977; Avrith and Mogenson, 1978), although differences do exist (Bernardis, 1985). The paradoxical finding that DMH inactivation also decreased feeding induced by intra-accumbens DAMGO may be explained in part by its suggested role as a possible mediator of the "activity balance" between the two hypothalamic feeding regions (Luiten et al., 1987). Interestingly, there are few or no direct intrinsic hypothalamic connections between the VMH and 
LH (Luiten and Room, 1980; Luiten et al., 1987; Thompson and Swanson, 1998), whereas the DMH has reciprocal connections to both (Luiten and Room, 1980). Considering the intermediary position of the $\mathrm{DMH}$, the effect produced by its inactivation may depend on the satiety level of the animal and specifically the current activity levels of both the VMH and LH. The current finding that inactivation of the DMH produces opposite effects on feeding behavior depending on whether there is intraaccumbens DAMGO activation may be explained by such a hypothesis. Indeed, it is known that the lateral hypothalamus is intensely activated during intra-accumbens DAMGO administration (Zhang and Kelley, 2000), whereas it is much less active during intra-accumbens saline control administration, even in the presence of food (Zhang and Kelley, 2000). Although the exact neurochemical nature of the interactions between hypothalamic nuclei are unknown, the present paradoxical finding may be explained by the DMH mediating the activity balance between the two critical hypothalamic nuclei controlling appetite; however, such a hypothesis awaits further testing.

Inactivation of the VTA also blocked the DAMGO-induced feeding response, implicating a role for mesolimbic dopaminergic neurons. The mesolimbic system consists of dopaminergic neurons projecting from the VTA to various limbic and forebrain areas such as the accumbens and has been shown to mediate locomotor activity, food and drug reinforcement, and general appetitive behaviors (Wise and Bozarth, 1985; Koob et al., 1992; Kiyatkin, 1995; Schilstrom et al., 1998; Tanda and Di Chiara, 1998). The finding that inhibition of the VTA blocks feeding induced by intra-accumbens DAMGO is consistent with findings that the two regions are anatomically and functionally linked (Nauta et al., 1978; Swanson, 1982; Herkenham et al., 1984; Schilstrom et al., 1998; Tanda and Di Chiara, 1998). In consideration of the inhibitory role of opioids on the excitability of accumbens neurons (Hamilton and Norgren, 1984; Hakan and Henriksen, 1987), the activation of the VTA produced by intraaccumbens DAMGO (Zhang and Kelley, 2000) might result from the disinhibition of dopaminergic neurons by inhibition of striatal GABAergic outputs. Given that intra-VTA muscimol has been shown previously to decrease dopamine release in the accumbens (Westerink et al., 1996), the present finding that intra-VTA muscimol blocked the feeding response further suggests a role of dopamine in intra-accumbens DAMGO-induced feeding. In line with this theory, it is conceivable that the degree to which intraaccumbens DAMGO increases feeding is correlated with the particular dopaminergic-activating nature of food (Bassareo and Di Chiara, 1999). This may partly explain why intra-accumbens DAMGO produces a more robust feeding response to highly palatable foods compared with the ingestion of less palatable foods.

Finally, inactivation of the NTS disrupted the opioid feeding response as well, suggesting the involvement of brainstem NTS neurons in mediating intra-accumbens opioid-induced feeding. We demonstrated previously that intra-accumbens DAMGO specifically activated neurons within the intermediate region of the NTS (Zhang and Kelley, 2000), which was the region targeted in the current study. Although the rostral division of the NTS receives the majority of gustatory input, the intermediate region does receive afferent inputs from superior laryngeal and glossopharyngeal nerves, as well as input from the rostral division of the NTS (Hamilton and Norgren, 1984). Bi-directional pathways have been shown to exist between the NTS and the accumbens, with NTS projections relaying taste information directly to the shell of the accumbens (Brog et al., 1993), and a descending pathway that possibly modulates taste processing in the NTS. The finding that inactivating the iNTS prevented the DAMGO-induced feeding response may suggest that intra-iNTS muscimol prevented a modulating signal from the accumbens. Baseline feeding was not reduced significantly after inactivation of the iNTS alone, further suggesting that the blockade of DAMGO-induced feeding was mediated via a disruption of an upstream signal.

It is important to address the use of muscimol as a method of neural inactivation as well as the possibility of its diffusion to areas outside the target region. Administration of muscimol has been a widely used method to induce temporary neural inactivation (Majchrzak and Di Scala, 2000), because its target receptor is widely distributed throughout the brain (Sieghart and Sperk, 2002) and it leaves fibers of passage unaffected. A previous study investigating the diffusion parameters of muscimol determined that $1 \mu \mathrm{l}$ of muscimol diffused $1.66 \mathrm{~mm}$ from the tip of the cannulas (Martin, 1991). Given the current study used a volume fourfold smaller, $0.25 \mu \mathrm{l}$, it is highly unlikely that areas outside the targeted region were affected.

The present findings demonstrate that the increased feeding produced by intra-accumbens $\mu$-opioid stimulation is dependent on the activation of a distributed network of brain regions. Indeed, inactivation of structures representing diencephalic, mesencephalic, and hindbrain regions completely prevented the feeding response induced by intra-accumbens DAMGO. Although this study is limited in its ability to suggest the neurochemical nature of the distributed network, it does provide the beginning framework for further analysis. We are also in the process of exploring the involvement of structures that project to the accumbens, such as the amygdala and gustatory cortex, which have shown projections that interact with the opioid-sensitive feeding zone within the accumbens.

\section{References}

Albert DJ, Storlien LH, Albert JG, Mah CJ (1971) Obesity following disturbance of the ventromedial hypothalamus: a comparison of lesions, lateral cuts, and anterior cuts. Physiol Behav 7:135-141.

Avrith D, Mogenson GJ (1978) Reversible hyperphagia and obesity following intracerebral microinjections of colchicine into the ventromedial hypothalamus of the rat. Brain Res 153:99-107.

Bakshi VP, Kelley AE (1993a) Feeding induced by opioid stimulation of the ventral striatum: role of opiate receptor subtypes. J Pharmacol Exp Ther 265:1253-1260.

Bakshi VP, Kelley AE (1993b) Striatal regulation of morphine-induced hyperphagia: an anatomical mapping study. Psychopharmacology 111:207-214.

Bassareo V, Di Chiara G (1999) Differential responsiveness of dopamine transmission to food-stimuli in nucleus accumbens shell/core compartments. Neuroscience 89:637-641.

Bellinger LL, Bernardis LL (1999) Effect of dorsomedial hypothalamic nuclei knife cuts on ingestive behavior. Am J Physiol 276:R1772-1779.

Bernardis LL (1985) Ventromedial and dorsomedial hypothalamic syndromes in the weanling rat: is the "center" concept really outmoded? Brain Res Bull 14:537-549.

Bernardis LL, Bellinger LL (1993) The lateral hypothalamic area revisited: neuroanatomy, body weight regulation, neuroendocrinology and metabolism. Neurosci Biobehav Rev 17:141-193.

Bernardis LL, Bellinger LL (1998) The dorsomedial hypothalamic nucleus revisited: 1998 update. Proc Soc Exp Biol Med 218:284-306.

Bittencourt JC, Presse F, Arias C, Peto C, Vaughan J, Nahon JL, Vale W, Sawchenko PE (1992) The melanin-concentrating hormone system of the rat brain: an immuno- and hybridization histochemical characterization. J Comp Neurol 319:218-245.

Braun J, Lasiter P, Kiefer S (1982) The gustatory neocortex of the rat. Physiol Psychol 10:13-45.

Brog JS, Salyapongse A, Deutch AY, Zahm DS (1993) The patterns of afferent innervation of the core and shell in the "accumbens" part of the rat ventral striatum: immunohistochemical detection of retrogradely transported fluoro-gold. J Comp Neurol 338:255-278. 
Carr KD (1996) Feeding, drug abuse, and the sensitization of reward by metabolic need. Neurochem Res 21:1455-1467.

Carr KD, Simon EJ (1984) Potentiation of reward by hunger is opioid mediated. Brain Res 297:369-373.

Choi S, Dallman MF (1999) Hypothalamic obesity: multiple routes mediated by loss of function in medial cell groups. Endocrinology 140:4081-4088.

Cooper S, Kirkham T (1993) Opioid mechanisms in the control of food consumption and taste preferences. In: Handbook of experimental pharmacology (Herz A, ed), pp 239-262. Berlin: Springer.

Cooper SJ (1983) Effects of opiate agonists and antagonists on fluid intake and saccharin choice in the rat. Neuropharmacology 22:323-328.

Drewnowski A, Krahn DD, Demitrack MA, Nairn K, Gosnell BA (1992) Taste responses and preferences for sweet high-fat foods: evidence for opioid involvement. Physiol Behav 51:371-379.

Dube MG, Kalra SP, Kalra PS (1999) Food intake elicited by central administration of orexins/hypocretins: identification of hypothalamic sites of action. Brain Res 842:473-477.

Elias CF, Saper CB, Maratos-Flier E, Tritos NA, Lee C, Kelly J, Tatro JB, Hoffman GE, Ollmann MM, Barsh GS, Sakurai T, Yanagisawa M, Elmquist JK (1998) Chemically defined projections linking the mediobasal hypothalamus and the lateral hypothalamic area. J Comp Neurol 402:442-459.

Giraudo SQ, Grace MK, Welch CC, Billington CJ, Levine AS (1993) Naloxone's anorectic effect is dependent on the relative palatability of food. Pharmacol Biochem Behav 46:917-921.

Glass MJ, Billington CJ, Levine AS (1999) Opioids and food intake: distributed functional neural pathways? Neuropeptides 33:360-368.

Haber S, Lynd E, Klein C, Groenewegen H (1990) Topographic organization of the ventral striatal efferent projections in the Rhesus monkey: an anterograde tracing study. J Comp Neurol 293:282-298.

Hakan RL, Henriksen SJ (1987) Systemic opiate administration has heterogeneous effects on activity recorded from nucleus accumbens neurons in vivo. Neurosci Lett 83:307-312.

Hamilton RB, Norgren R (1984) Central projections of gustatory nerves in the rat. J Comp Neurol 222:560-577.

Heimer L, Zahm DS, Churchill L, Kalivas PW, Wohltmann C (1991) Specificity in the projection patterns of accumbal core and shell in the rat. Neuroscience 41:89-125.

Herkenham M, Edley SM, Stuart J (1984) Cell clusters in the nucleus accumbens of the rat, and the mosaic relationship of opiate receptors, acetylcholinesterase and subcortical afferent terminations. Neuroscience 11:561-593.

Johnson PI, Stellar JR, Paul AD (1993) Regional reward differences within the ventral pallidum are revealed by microinjections of a mu opiate receptor agonist. Neuropharmacology 32:1305-1314.

Kelley AE, Bakshi VP, Haber SN, Steininger TL, Will MJ, Zhang M (2002) Opioid modulation of taste hedonics within the ventral striatum. Physiol Behav 76:365-377.

Kelly J, Alheid GF, Newberg A, Grossman SP (1977) GABA stimulation and blockade in the hypothalamus and midbrain: effects on feeding and locomotor activity. Pharmacol Biochem Behav 7:537-541.

Kiyatkin EA (1995) Functional significance of mesolimbic dopamine. Neurosci Biobehav Rev 19:573-598.

Koob GF, Maldonado R, Stinus L (1992) Neural substrates of opiate withdrawal. Trends Neurosci 15:186-191.

Levine AS, Billington CJ (1989) Opioids. Are they regulators of feeding? Ann NY Acad Sci 575:209-219.

Luiten PG, Room P (1980) Interrelations between lateral, dorsomedial and ventromedial hypothalamic nuclei in the rat. An HRP study. Brain Res 190:321-332.

Luiten PG, ter Horst GJ, Steffens AB (1987) The hypothalamus, intrinsic connections and outflow pathways to the endocrine system in relation to the control of feeding and metabolism. Prog Neurobiol 28:1-54.

Majchrzak M, Di Scala G (2000) GABA and muscimol as reversible inactivation tools in learning and memory. Neural Plast 7:19-29.

Martin JH (1991) Autoradiographic estimation of the extent of reversible inactivation produced by microinjection of lidocaine and muscimol in the rat. Neurosci Lett 127:160-164.

Martin W, Wikler A, Eades C, Pescor F (1963) Tolerance to and physical dependence on morphine in rats. Psychopharmacologia 4:247-260.

Mucha RF, Iversen SD (1986) Increased food intake after opioid microin- jections into nucleus accumbens and ventral tegmental area of rat. Brain Res 397:214-224.

Nauta WJ, Smith GP, Faull RL, Domesick VB (1978) Efferent connections and nigral afferents of the nucleus accumbens septi in the rat. Neuroscience 3:385-401.

Paxinos G, Watson C (1998) The rat brain in stereotaxic coordinates. New York: Academic.

Peyron C, Tighe DK, van den Pol AN, de Lecea L, Heller HC, Sutcliffe JG, Kilduff TS (1998) Neurons containing hypocretin (orexin) project to multiple neuronal systems. J Neurosci 18:9996-10015.

Qu D, Ludwig DS, Gammeltoft S, Piper M, Pelleymounter MA, Cullen MJ, Mathes WF, Przypek R, Kanarek R, Maratos-Flier E (1996) A role for melanin-concentrating hormone in the central regulation of feeding behaviour. Nature 380:243-247.

Sakurai T, Amemiya A, Ishii M, Matsuzaki I, Chemelli RM, Tanaka H, Williams SC, Richardson JA, Kozlowski GP, Wilson S, Arch JR, Buckingham RE, Haynes AC, Carr SA, Annan RS, McNulty DE, Liu WS, Terrett JA, Elshourbagy NA, Bergsma DJ, Yanagisawa M (1998) Orexins and orexin receptors: a family of hypothalamic neuropeptides and $G$ proteincoupled receptors that regulate feeding behavior. Cell 92:573-585.

Schilstrom B, Svensson HM, Svensson TH, Nomikos GG (1998) Nicotine and food induced dopamine release in the nucleus accumbens of the rat: putative role of alpha7 nicotinic receptors in the ventral tegmental area. Neuroscience 85:1005-1009.

Sieghart W, Sperk G (2002) Subunit composition, distribution and function of $\mathrm{GABA}(\mathrm{A})$ receptor subtypes. Curr Top Med Chem 2:795-816.

Stanley BG, Lanthier D, Leibowitz SF (1988) Multiple brain sites sensitive to feeding stimulation by opioid agonists: a cannula-mapping study. Pharmacol Biochem Behav 31:825-832.

Swanson LW (1982) The projections of the ventral tegmental area and adjacent regions: a combined fluorescent retrograde tracer and immunofluorescence study in the rat. Brain Res Bull 9:321-353.

Sweet DC, Levine AS, Billington CJ, Kotz CM (1999) Feeding response to central orexins. Brain Res 821:535-538.

Tanda G, Di Chiara G (1998) A dopamine-mul opioid link in the rat ventral tegmentum shared by palatable food (Fonzies) and non-psychostimulant drugs of abuse. Eur J Neurosci 10:1179-1187.

Thompson RH, Swanson LW (1998) Organization of inputs to the dorsomedial nucleus of the hypothalamus: a reexamination with Fluorogold and PHAL in the rat. Brain Res Brain Res Rev 27:89-118.

Welch CC, Kim EM, Grace MK, Billington CJ, Levine AS (1996) Palatability-induced hyperphagia increases hypothalamic dynorphin peptide and mRNA levels. Brain Res 721:126-131.

Weldon DT, O'Hare E, Cleary J, Billington CJ, Levine AS (1996) Effect of naloxone on intake of cornstarch, sucrose, and polycose diets in restricted and nonrestricted rats. Am J Physiol 270:R1183-1188.

Westerink BH, Kwint HF, deVries JB (1996) The pharmacology of mesolimbic dopamine neurons: a dual-probe microdialysis study in the ventral tegmental area and nucleus accumbens of the rat brain. J Neurosci 16:2605-2611.

Williams G, Harrold JA, Cutler DJ (2000) The hypothalamus and the regulation of energy homeostasis: lifting the lid on a black box. Proc Nutr Soc 59:385-396.

Wise RA, Bozarth MA (1985) Brain mechanisms of drug reward and euphoria. Psychiatr Med 3:445-460.

Wright CI, Groenewegen HJ (1996) Patterns of overlap and segregation between insular cortical, intermediodorsal thalamic and basal amygdaloid afferents in the nucleus accumbens of the rat. Neuroscience 73:359-373.

Yeomans MR, Gray RW (1996) Selective effects of naltrexone on food pleasantness and intake. Physiol Behav 60:439-446.

Yeomans MR, Gray RW (1997) Effects of naltrexone on food intake and changes in subjective appetite during eating: evidence for opioid involvement in the appetizer effect. Physiol Behav 62:15-21.

Zhang M, Kelley AE (1997) Opiate agonists microinjected into the nucleus accumbens enhance sucrose drinking in rats. Psychopharmacology (Berl) $132: 350-360$

Zhang M, Kelley AE (2000) Enhanced intake of high-fat food following striatal mu-opioid stimulation: microinjection mapping and fos expression. Neuroscience 99:267-277.

Zhang M, Gosnell BA, Kelley AE (1998) Intake of high-fat food is selectively enhanced by mu opioid receptor stimulation within the nucleus accumbens. J Pharmacol Exp Ther 285:908-914. 